\title{
Investigating the Link between Lynch Syndrome and Breast Cancer
}

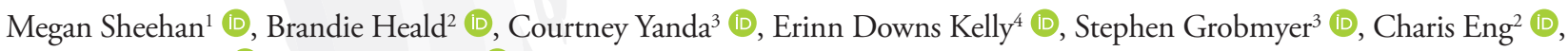 \\ Matthew Kalady ${ }^{5}$ (D), Holly Pederson ${ }^{3}$ (D) \\ ${ }^{1}$ Cleveland Clinic, Lerner College of Medicine, Cleveland, OH, USA \\ ${ }^{2}$ Cleveland Clinic, Genomic Medicine Institute, Cleveland, OH, USA \\ ${ }^{3}$ Cleveland Clinic, Breast Services Department, Cleveland, OH, USA \\ ${ }^{4}$ Cleveland Clinic, RJ Tomsich Pathology and Laboratory Medicine Institute, Cleveland, OH, USA \\ ${ }^{5}$ Cleveland Clinic, Department of Colorectal Surgery, Cleveland, OH, USA
}

\begin{abstract}
Objective: Lynch syndrome is an inherited genetic disorder associated with a predisposition to early-onset colorectal and endometrial cancers, but breast cancer risk in these patients is debated. The aim of this study is to evaluate breast cancer rates in a cohort of Lynch syndrome patients, as well as to identify women who may be eligible for additional breast cancer specific genetic testing or enhanced breast surveillance (contrast-enhanced magnetic resonance imaging (MRI) screening).

Materials and Methods: Using a hereditary colorectal cancer registry at a single academic institution for identification of patients with Lynch syndrome, a retrospective chart review was performed of 188 women with DNA mismatch repair (MMR) mutations. The Tyrer-Cuzick model was used to estimate breast cancer risk in patients without breast cancer.

Results: The prevalence of breast cancer differed based on mutation type ( $\mathrm{p}=0.0043$ ), as $27 \%$ of women with a PMS2 mutation were diagnosed with breast cancer, compared to 3\%, 4\%, and 9\% in MLH1, MSH2, and MSH6 patients. The average age at diagnosis for women with a PMS2 mutation was 46.7 years. Additionally, $7.5 \%$ of unaffected women had an estimated lifetime risk of breast cancer greater than 20\%. 46/188 (24.4\%) of patients were eligible for breast specific genetic testing.

Conclusion: Our analysis suggests that Lynch syndrome patients with PMS2 mutations may be at higher risk of developing breast cancer. Additionally, the personal and family history of cancer suggests crossover in eligibility for breast specific genetic testing in a significant number of patients (16.5-24.4\%). Also, many women are eligible for enhanced breast surveillance (7.5\%) which would otherwise not be offered.
\end{abstract}

Keywords: Breast neoplasms, cancer screening, colorectal cancer hereditary nonpolyposis

Cite this articles as: Sheehan M, Heald B, Yanda C, Kelly ED, Grobmyer S, Eng C, et al. Investigating the Link between Lynch Syndrome and Breast Cancer. Eur J Breast Health 2020; 16(2): 106-109.

\section{Introduction}

Lynch syndrome is an inherited cancer-susceptibility disorder caused by pathogenic germline variants in DNA mismatch repair (MMR) genes, including MLH1, MSH2, MSH6, and PMS2. Historically known as hereditary nonpolyposis colorectal cancer, this syndrome is associated with increased risk for a multitude of cancers, including colorectal, endometrial, ovarian, small bowel, urothelium, biliary tract, and stomach (1-3). Lynch syndrome affects 1 in 279 individuals, and is more common than Hereditary Breast and Ovarian Cancer Syndrome caused by BRCA1 and BRCA2 mutations $(4,5)$. Lynch syndrome is also inherited in an autosomal dominant fashion. Recent studies have suggested that breast cancer may be included in the spectrum of Lynch syndrome-associated cancers, but the evidence is controversial. Cohort studies have found significantly increased age-specific incidence rate ratios of breast cancer in Lynch patients $(6,7)$. Case series have also shown high prevalence of breast cancer in Lynch populations, with earlier age of diagnosis compared to the general population (8). Investigators have looked at microsatellite instability, immunohistochemistry and mismatch repair gene deficiency in breast cancers of Lynch syndrome patients, suggesting that patients with Lynch syndrome are more likely to exhibit microsatellite instability and MMR protein loss compared with sporadic breast cancers (9-11). However, other studies show no association and recommend that increased surveillance is not indicated for Lynch syndrome patients $(1,12,13)$.

Multigene panel testing has provided new insight, suggesting that individuals with MSH6 and PMS2 mutations may have a higher risk for breast cancer $(14,15)$. A case-control study published by Couch showed that only MSH6 mutations were associated with a statisti- 
Table 1. Mismatch repair gene distribution and characteristics in the Lynch syndrome cohort

\begin{tabular}{|lcccc} 
& MLH1 & MSH2 & MSH6 & PMS2 \\
\hline Cohort size & 58 & 70 & 34 & 26 \\
Race (\% white) & 94.8 & 90 & 100 & 92.3 \\
Age (mean \pm SD) & $51.8 \pm 15.8$ & $54.7 \pm 12.8$ & $54.2 \pm 14.0$ & $53.8 \pm 12.5$ \\
\hline SD: standard deviation & & & &
\end{tabular}

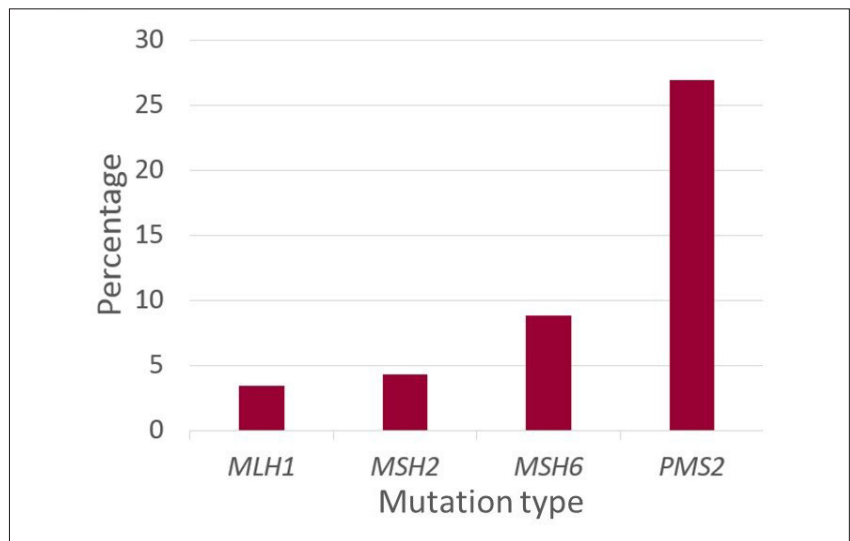

Figure 1. Percentage of women diagnosed with breast cancer by mutation type. $27 \%$ of PMS2 mutation carriers were diagnosed with breast cancer, which was greater than other mutation types $(p=0.0043)$

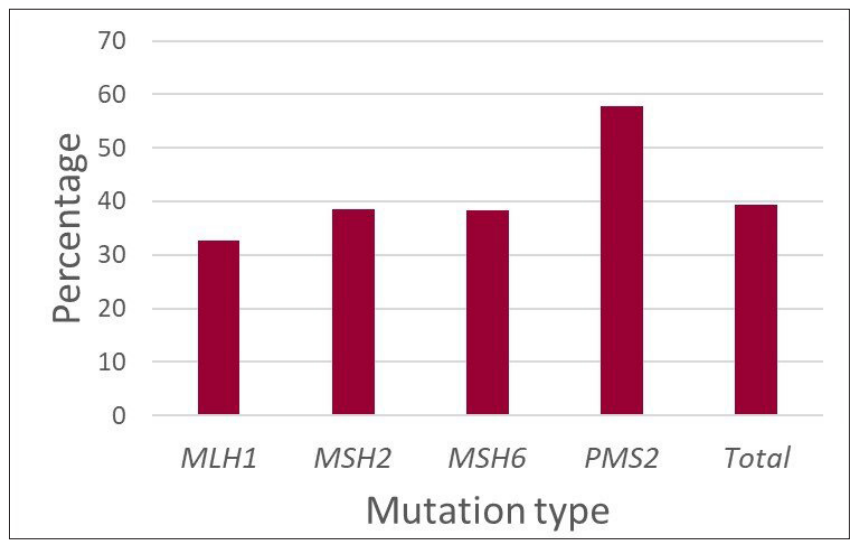

Figure 2. Percentage of women who had a family history of breast cancer, including first- and second-degree relatives. There were not significant differences between mutation type $(p>0.05)$

\section{Key Points}

- The link between breast cancer and Lynch syndrome has been debated in the literature, however no studies have looked at appropriate surveillance and risk-reducing methods in Lynch syndrome patients.

- In this cohort, patients with PMS2 mutations had a significantly higher prevalence of breast cancer compared with other mutation types.

- Many Lynch syndrome patients qualify for breast-specific genetic testing, and $7.5 \%$ of patients without breast cancer in this study qualified for enhanced surveillance for breast cancer. We may be missing an opportunity to fully screen and reduce risk in this patient population.

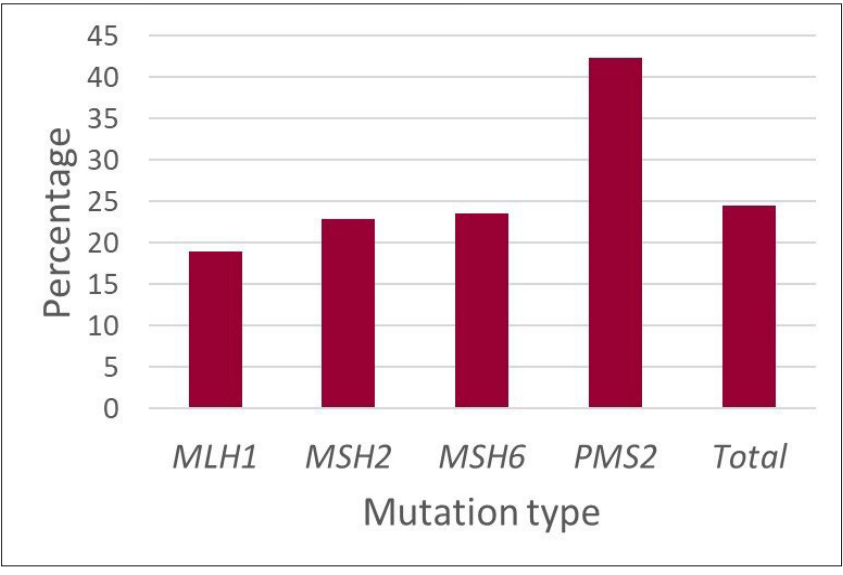

Figure 3. Percentage of women who qualified for breast-specific genetic testing, based on NCCN guidelines (v 2.2019). There were not significant differences between mutation type $(p>0.05)$

cally significantly increased risk for breast cancer with an OR of 1.93 (1.16-3.27) and PMS2 mutations were not associated with increased risk (13).

Conflicting studies have made it difficult to assess breast cancer risk in Lynch syndrome patients, and the possible mechanistic association between Lynch syndrome and breast cancer remains unclear. However, studies have not evaluated whether or not these patients are being offered appropriate surveillance and risk reducing measures based on tools used clinically to evaluate women for breast cancer risk. This study aims to address this question, as well as adding to the body of existing literature by assessing breast cancer rates by gene in our cohort. Utilizing hereditary colorectal cancer registry at a single academic institution, a cohort of 188 women with $M M R$ mutations was identified. This cohort was examined for breast cancer prevalence based on mutation type, as well as qualification for breast-specific genetic testing and enhanced breast surveillance utilizing current national guidelines and clinically available risk assessment tools.

\section{Materials and Methods}

\section{Study population}

The hereditary colorectal cancer registry at a single academic institution was used to identify women who were above age 18 with germline $M M R$ variants. Informed consent was obtained from patients at the time of enrolment in the registry. Institutional review board committee approval was obtained for the study. Retrospective chart review was performed utilizing the electronic medical record to select women with breast cancer from this population and extract demographic information, breast cancer characteristics, and personal and family history of other cancers. 


\section{Statistical analysis}

Breast cancer risk estimations were run using the Tyrer-Cuzick model (v8) (16). The National Comprehensive Cancer Network (NCCN) Practice Guidelines-Genetic/Familial High-Risk Assessment: Breast and Ovarian, version 2.2019 was used to identify women eligible for breast-specific genetic testing (17). Descriptive statistical analyses were conducted separately for MLH1, MSH2, MSH6, and PMS2 genes. Statistical tests were performed using RProject (R Foundation for Statistical Computing, Vienna, Austria) (18). Nominal variables were assessed using 2-tailed chi-squared analyses or Fisher's exact analyses.

\section{Results}

The series included 188 women with Lynch syndrome. It included women with pathogenic variants in MLH1 ( $\mathrm{n}=58)$, MSH2 $(\mathrm{n}=70)$, MSH6 (n=34), and PMS2 ( $\mathrm{n}=26$; Table 1). Of the 188 women, 16 had a previous diagnosis of breast cancer at the time of the study. Of the 26 women with PMS2 mutations, $27 \%$ had a history of breast cancer which was significantly greater than women with other mutation types ( $\mathrm{p}=0.0043$, Figure 1). Women with PMS2 mutations who developed breast cancer had an average age of diagnosis of 46.7 years old. Overall, $39.3 \%$ of the study population had a family history of breast cancer, incorporating first- and second-degree relatives (Figure 2).

Of the 172 Lynch syndrome patients without a previous diagnosis of breast cancer, $7.5 \%$ had an estimated lifetime risk of breast cancer (using the Tyrer-Cuzick model v8) greater than 20\%, meeting criteria for screening breast magnetic resonance imaging (MRI) per NCCN, American Cancer Society, and American College of Radiology guidelines $(17,19,20)$.

Patients who qualified for breast-specific genetic testing were identified using NCCN Practice Guidelines (17). Overall, 24.4\% of all Lynch syndrome mutation carriers were eligible for breast specific testing (Figure 3). As pancreatic cancer and ovarian cancer overlap between the two syndromes, when excluding patients who only met criteria based on a personal or family history of these cancers, $16.5 \%$ met criteria for breast specific genetic testing.

\section{Discussion}

This study examined the association between Lynch syndrome mutation type and breast cancer, evaluated women with Lynch syndrome for their estimated lifetime risk of breast cancer development, and determined eligibility for breast-specific genetic testing. We found that the prevalence of breast cancer in PMS2 mutation carriers was significantly higher in this cohort when compared to other mutation types. With regard to family history of breast cancer, $57.7 \%$ of women with PMS2 mutations had a first- or second-degree relative diagnosed with breast cancer. Other studies have found a similar association $(14,21)$. We also found that these women were diagnosed with breast cancer at an average age of 46.7 years old, which is younger than that of the general population (22). This topic warrants future study with larger diverse multicentre cohorts of patients with Lynch syndrome studied prospectively, as breast cancer is a common disease and current data come mainly from Caucasian populations.

Many women with Lynch syndrome qualified for breast-specific genetic testing by NCCN guidelines, and $7.5 \%$ of women without breast cancer were eligible for enhanced surveillance based on the TyrerCuzick risk assessment tool. This presents significant implications for typically not routinely assessed for breast cancer risk in a clinical setting. However, many of these women may be eligible for screening MRI surveillance or other opportunities for breast cancer risk reduction. We may be missing an opportunity to fully assess cancer risk in these patients, which impacts screening and risk reduction strategies.

This study utilized a comprehensive registry with a large population of Lynch mutation carriers. There are some limitations, including that groups were compared without a population control, which limits the inferences that can be made about Lynch syndrome and breast cancer risk compared to that of the general population. The registry may have also included related families or family members, which was not accounted for in this study. Future directions include looking at the pathology of breast cancers with Lynch syndrome to examine the frequency of microsatellite instability (which may be important therapeutically) (23), immunohistochemistry and others, in order to determine if breast cancers in Lynch syndrome patients have specific pathologic features, further supporting the hypothesis of a genetic association and possible causation. Further, cancer specific risks for Lynch syndrome patients, including that for breast cancer, need to be clarified.

Ethics Committee Approval: Ethics committee approval was received for this study from the ethics committee of Cleveland Clinic.

Informed Consent: Written informed consent was obtained from patients who participated in this study.

Peer-review: Externally peer-reviewed.

Author Contributions: Concept - M.S., H.P., M.K.; Design - M.S., H.P.; Supervision - H.P., S.G., M.K.; Resources - M.K., C.E., E.D.K.; Materials - M.K., B.H.; Data Collection and/or Processing - M.S., C.Y.; Analysis and/ or Interpretation - M.S., H.P.; Literature Search - M.S., H.P.; Writing Manuscript - M.S., H.P.; Critical Review - C.E., B.H., E.D.K., S.G.

Acknowledgements: We thank Lauren Bolden for her assistance with database management for this project.

Conflict of Interest: The authors have no conflicts of interest to declare.

Financial Disclosure: The authors declared that this study has received no financial support.

\section{References}

1. Watson P, Vasen HFA, Mecklin JP, Bernstein I, Aarnio M, Järvinen HJ, et al. The risk of extra-colonic, extra-endometrial cancer in the Lynch syndrome. Int J Cancer 2008; 123: 444-449. (PMID: 18398828) [CrossRef]

2. Lynch HT, de la Chapelle A. Hereditary Colorectal Cancer [Internet]. http://dx.doi.org.ccmain.ohionet.org/10.1056/NEJMra012242. 2009 [cited 2019 Apr 25]. Available from: http://www.nejm.org/doi/10.1056/ NEJMra012242?url_ver=Z39.88-2003\&rfr_id=ori\%3Arid\%3Acrossref. org\&rfr_dat=cr_pub\%3Dwww.ncbi.nlm.nih.gov

3. Bonadona V, Bonaïti B, Olschwang S, Grandjouan S, Huiart L, Longy M, et al. Cancer Risks Associated With Germline Mutations in MLH1, MSH2, and MSH6 Genes in Lynch Syndrome. JAMA 2011; 305: 23042310. (PMID: 21642682) [CrossRef]

4. Win AK, Jenkins MA, Dowty JG, Antoniou AC, Lee A, Giles GG, et al. Prevalence and Penetrance of Major Genes and Polygenes for Colorectal Cancer. Cancer Epidemiol Biomarkers Prev 2017; 26: 404-412. (PMID: 27799157) [CrossRef]

5. Malone KE, Daling JR, Doody DR, Hsu L, Bernstein L, Coates RJ, et al. Prevalence and predictors of BRCA1 and BRCA2 mutations in a popula- 
tion-based study of breast cancer in white and black american women ages 35 to 64 years. Cancer Res 2006; 66: 8297-8308. (PMID: 16912212) [CrossRef]

6. Therkildsen C, Ladelund S, Smith-Hansen L, Lindberg LJ, Nilbert M. Towards gene- and gender-based risk estimates in Lynch syndrome; agespecific incidences for 13 extra-colorectal cancer types. Br J Cancer 2017; 117: 1702-1710. (PMID: 29065108) [CrossRef]

7. Harkness EF, Barrow E, Newton K, Green K, Clancy T, Lalloo F, et al. Lynch syndrome caused by MLH1 mutations is associated with an increased risk of breast cancer: a cohort study. J Med Genet 2015; 52: 553556. (PMID: 26101330) [CrossRef]

8. da Silva FC, de Oliveira LP, Santos ÉM, Nakagawa WT, Aguiar Junior $\mathrm{S}$, Valentin MD, et al. Frequency of extracolonic tumors in Brazilian families with Lynch syndrome: analysis of a hereditary colorectal cancer institutional registry. Fam Cancer 2010; 9: 563-570. (PMID: 20697958) [CrossRef]

9. Buerki N, Gautier L, Kovac M, Marra G, Buser M, Mueller H, et al. Evidence for breast cancer as an integral part of Lynch syndrome. Genes Chromosomes Cancer 2012; 51: 83-91. (PMID: 22034109) [CrossRef]

10. Walsh MD, Buchanan DD, Cummings MC, Pearson SA, Arnold ST, Clendenning $\mathrm{M}$, et al. Lynch syndrome-associated breast cancers: clinicopathologic characteristics of a case series from the colon cancer family registry. Clin Cancer Res 2010; 16: 2214-2224. (PMID: 20215533)

11. Win AK, Lindor NM, Jenkins MA. Risk of breast cancer in Lynch syndrome: a systematic review. Breast Cancer Res 2013; 15: R27. (PMID: 23510156) [CrossRef]

12. Müller A, Edmonston TB, Corao DA, Rose DG, Palazzo JP, Becker H, et al. Exclusion of breast cancer as an integral tumor of hereditary nonpolyposis colorectal cancer. Cancer Res 2002; 62: 1014-1019.

13. Couch FJ, Shimelis H, Hu C, Hart SN, Polley EC, Na J, et al. Associations between cancer predisposition testing panel genes and breast cancer. JAMA Oncol 2017; 3: 1190-1196. (PMID: 28418444) [CrossRef]
14. Roberts ME, Jackson SA, Susswein LR, Zeinomar N, Ma X, Marshall ML, et al. MSH6 and PMS2 germ-line pathogenic variants implicated in Lynch syndrome are associated with breast cancer. Genet Med 2018; 20: 1167-1174. (PMID: 29345684) [CrossRef]

15. Espenschied CR, LaDuca H, Li S, McFarland R, Gau CL, Hampel H. Multigene panel testing provides a new perspective on lynch syndrome. J Clin Oncol 2017; 35: 2568-2575. (PMID: 28514183) [CrossRef]

16. Cuzick J. IBIS Breast Cancer Risk Evaluation Tool [Internet]. 2017. Available from: http://www.ems-trials.org/riskevaluator/

17. National Comprehensive Cancer Network. NCCN Practice Guidelines: Genetic/Familial High-Risk Assessment: Breast and Ovarian. 2019;

18. R Core Team (2014). R: A language and environment for statistical computing. R Foundation for Statistical Computing, Vienna, Austria. URL http://www.R-project.org/.

19. Saslow D, Boetes C, Burke W, Harms S, Leach MO, Lehman CD, et al. American Cancer Society guidelines for breast screening with MRI as an adjunct to mammography. CA Cancer J Clin 2007; 57: 75-89. (PMID: 17392385) [CrossRef]

20. Monticciolo DL, Newell MS, Moy L, Niell B, Monsees B, Sickles EA. Breast cancer screening in women at higher-than-average risk: Recommendations from the ACR. J Am Coll Radiol 2018; 15: 408-414. (PMID: 29371086) [CrossRef]

21. ten Broeke SW, Brohet RM, Tops CM, van der Klift HM, Velthuizen ME, Bernstein I, et al. Lynch Syndrome caused by germline PMS2 mutations: Delineating the cancer risk. J Clin Oncol 2014; 33: 319-325. (PMID: 25512458) [CrossRef]

22. American Cancer Society. Breast Cancer Facts \& Figures 2017-2018. Atlanta: American Cancer Society, Inc. 2017.

23. Le DT, Uram JN, Wang H, Bartlett BR, Kemberling H, Eyring AD, et al. PD-1 Blockade in Tumors with Mismatch-Repair Deficiency. N Engl J Med 2015; 372: 2509-2520. (PMID: 26028255) 